\title{
Influence of the Mechanical and Metallurgical State of an Al-Mg Alloy on the Surface Integrity in Ultraprecision Machining
}

This work presents the experimental results of the facing turning of an Al-Mg alloy. This aluminium alloy was mechanically and metallurgically modified, by means of cold rolling reduction and refining grain size previous to machining. The samples were cut and compared with samples in the as-received form, machined under the same cutting conditions. Surface finishing and work hardening were measured. Results show that theoretical surface roughness values are always smaller than the measured ones for all samples. Also, the surface roughness of the as-received samples is larger than that of mechanically modified samples. This difference of surface roughness was attributed to the swelling effect of the material. Microhardness values of the machined samples showed a decreasing trend with increasing loads. The surface of the cold rolled sample did not present a detectable microhardness alteration. Optical microscopy was used to observe qualitative aspects of the machined surface.

Keywords: Ultraprecision, Diamond Tools, Surface Finish, Surface Integrity, Turning

\section{Introduction}

In recent years, ultraprecision machining has been considered a feasible machining technique for the fabrication of high-quality mirror-like surfaces. The typical cutting conditions in ultraprecision diamond turning implies that material removal process be governed by the micro interaction between the diamond cutting edge and the workpiece material. Because of this, the microstructure of the workpiece can play a fundamental role in the cutting results.

The effect of material properties on the microcutting mechanism is considered extremely important. Some of them were reported in Jasinevicius et al. (1999), which shows that the machining of polycrystalline materials involves interesting aspects related to tool/material interaction. This interaction may result in changing to the outmost layer introducing damage to this portion of the workpiece. Figure 1 is a schematic diagram depicting the machined surface contact with the tool flank face behind the cutting edge.

Although it is well established that single point diamond turning introduces very little damage to the machined surface, even small strain hardening may contribute to affect the performance of the machined component. Duduch et al. (2000) showed that the final form of the machined surface depends on the number of passes and depth of cut. According to them, as the depth of cut increases the burnishing caused by the friction between the generated surface and the tool flank face may contribute to the strain elastic recovery of the crystal grains and subsequent stress relief of these grains. The quantification of the stress state of the (remnant) remaining damaged surface layer may offer important information on the performance of a machined component. According to the works of Evans et al. (1987) and Horio et al. (1992), the depth of the damaged layer in non-ferrous metals $(\mathrm{Al}, \mathrm{Cu}$, etc.) machined with very sharp single point diamond tools may range from 1 up to 17 $\mu \mathrm{m}$.

Paper accepted July, 2003. Technical Editor: Alisson Rocha Machado.

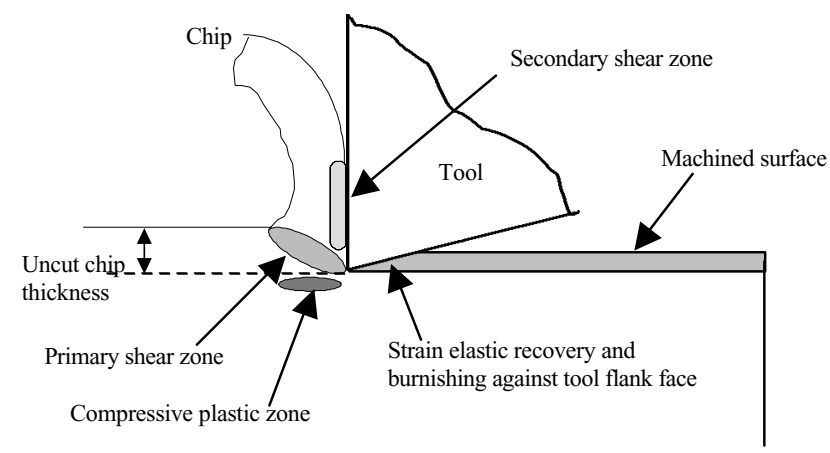

Figure 1. Schematic diagram of the burnishing effect caused by swelling of the material. The contact between the generated surface and the tool flank face is due to the strain elastic recovery of the material.

On the other hand, very little has been investigated on how a modified material both, metallurgically and mechanically, can affect the machining response in ultraprecision diamond turning.

The objective of this paper is to present experimental results obtained from single point diamond turning of an Al-Mg alloy, mechanically and metallurgically modified. Two different samples were tested with the same cutting conditions (feedrate and depth of cut): samples with grain size reduction and cold rolled (reduction of $80 \%$ ) samples. Surface roughness and microhardness measurements were taken in order to evaluate surface integrity. A natural single crystal diamond tool with cutting edge sharpness in the submicrometre range was used in all cutting tests.

\section{Theoretical Background}

Polycrystalline metals are stronger than their single crystal equivalents, which means that greater stresses are required to initiate slip and attendant yielding. Even though a single grain may be favorably oriented with the applied stress for slip, it cannot deform until the adjacent and less favorably oriented grains are capable of slipping; this requires a higher applied stress level (Callister, 1994). Consequently, the chip formation may bring some understanding to the surface generation mechanism. Grain crystallographic orientation may result in both different grain heights and, consequently, chip thickness variation. This difference in chip 
thickness may be caused by shear angle change from grain-to-grain, since this angle is affected by material properties such as elastic modulus (E).

These anisotropy effects may be attenuated during ultraprecision machining by different manners, such as: diamond tools with larger nose radius, positive rake angles and increasing material strength. The latter is supported by the assumption that anisotropy may be attenuated or even eliminated by means of grain refining or strain hardening the material before machining.

It is well established that the ability of a metal to plastically deform depends on the ability of a dislocation to move. Furthermore, macroscopic plastic deformation corresponds to the generation of large numbers of dislocations. Since hardness and strength (both yield and tensile) are related to the ease with which plastic deformation can be made to occur, by reducing the mobility of dislocations, the mechanical strength may be enhanced, that is, greater mechanical forces will be required to initiate plastic deformation (Callister, 1994).

Considering the above, it is accepted that grain refining could be seen as a possibility of achieving better response to the tool/material interaction. When cutting a larger number of grains simultaneously, chatter vibrations due to the crystallographic change may be attenuated (Furukawa \& Moronuki 1988). Once plastic deformation corresponds to the motion of a large numbers of dislocations, hindering its mobility by means of increasing grain boundary area, increases material strength as well.

In addition, when material is strain hardened, its strength will also increase by means of hindering dislocation to move by previous generation of a large number of other dislocations. Manufacturing operations such as cold rolling could be used in order to make the properties of a polycrystalline aggregate homogeneous. This would provide texture to the crystal grains, i.e., grains with preferential orientation (Sato et al. 1983).

In conclusion, both fine grain structure and work hardened materials have larger yield strength and as a result lower effect of material's anisotropy.

\section{Experimental Details}

Single point diamond turning tests were carried out on a commercially available diamond turning machine, the Aspheric Surface Generator Rank Pneumo ASG 2500. This is a T-base carriage configuration and carriages (hydrostatic bearing, driven by pulse-width-modulated dc servomotors, rotary-to-linear motion through $5 \mathrm{~mm}$ pitch ballscrews and position feedback using laser interferometer).

Three samples of the same Al-Mg alloy were used in the tests. One with the microstructure as received (ar), one with grain size reduction and one cold rolled with $80 \%$ reduction. Initially the grain size of the sample was approximately 100-200 $\mu \mathrm{m}$. The original Vickers microhardness of the three samples were, respectively, $\mathrm{Hv}=$ $65 \mathrm{kgf} / \mathrm{mm}^{2}, \mathrm{Hv}=70 \mathrm{kgf} / \mathrm{mm}^{2}$ and $110 \mathrm{kgf} / \mathrm{mm}^{2}$. The sample with as-received microstructure was used in the tests in order to provide a refence to guide the trends observed in the machining results.

Figures 2-a and 2-b show photomicrographs of the as-received (TGar) and reduced grain size $\left(\mathrm{TG}_{\text {small }}\right)$ samples, chemically etched with Kellers reagent (etchants). The grain size reduction was obtained by first making a cold rolling ( $80 \%$ reduction) and then an annealing heat treatment of the work hardened sample in a furnace at the temperature of $350^{\circ} \mathrm{C}$ during $35 \mathrm{~min}$, and then cooled in distilled water at room temperature. The grain size reduction was estimated to be in the range of $30 \mu \mathrm{m}$. The photomicrgraphs of the samples do not present an equiaxial grain microstructure.

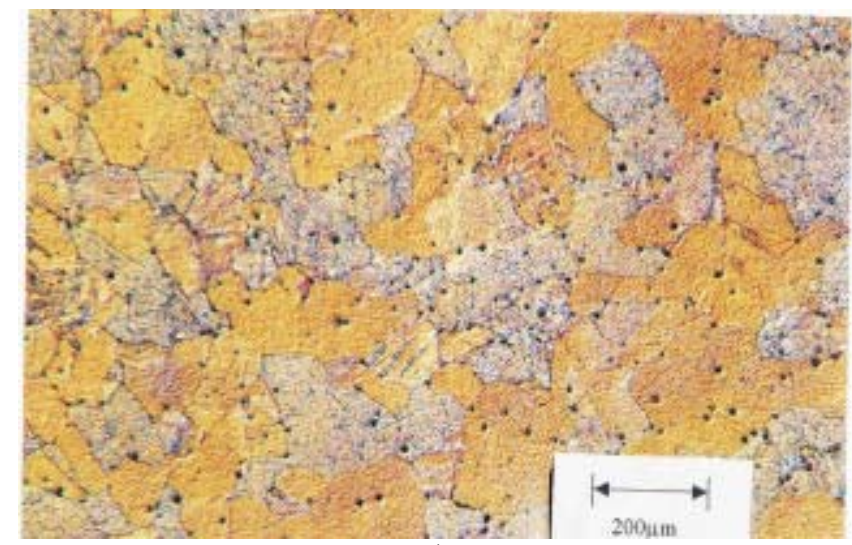

a)

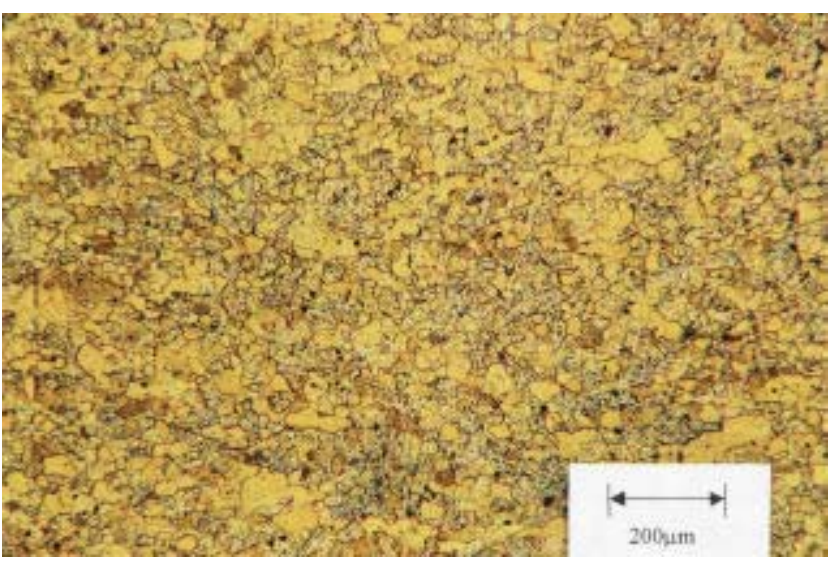

b)

Figure 2. Photomicrograph made by optical microscopy of two different sample a) as-received sample and; b) the recrystallized sample showing smaller grain size (magnification $100 \mathrm{x}$ ).

The other sample was cold rolled with the same reduction. All samples were face cut. Table 1 describes the experimental conditions and tool geometry used in the cutting tests. The machining tests were carried out in order to observe the influence of the cutting conditions on the surface finish and surface integrity. The first part of the tests consisted of varying the feedrate and keeping the depth of cut constant at $10 \mu \mathrm{m}$. In the second part of the cutting tests, the feedrate was kept constant at $15 \mu \mathrm{m} / \mathrm{rev}$ and the depth of cut was varied.

After machining with each combination of cutting parameters, i.e., feedrate and depth of cut, the microtopography of the surface was inspected by means of mechanical profilometer. The surface roughness was measured over a sampling length of $0.56 \mathrm{~mm}$ and cut-off length of $0.08 \mathrm{~mm}$. The evaluating length was chosen according to NBR 6405/1988. Form Talysurf 120 L Rank Taylor Robson was used to perform the roughness measurement. The stylus nose radius was $2.5 \mu \mathrm{m}$. Average results of four repeated tests are plotted.

Table 1. Tool geometry and dimensions used in the cutting tests.

\begin{tabular}{lc}
\hline Tool geometry and cutting conditions & Dimensions \\
\hline Tool material & Single crystal diamond \\
Tool nose radius $(\mathrm{mm})$ & $1.52 \mathrm{~mm}$ \\
Rake angle $\left({ }^{\circ}\right)$ & 0 \\
Clearance angle $\left(^{\circ}\right)$ & 12 \\
Feed rate $(\mu \mathrm{m} / \mathrm{rev})$ & $5,10,15$ and 30 \\
Depth of cut $(\mu \mathrm{m})$ & $5,10,15$ and 30 \\
\hline
\end{tabular}


The selected parameter used to evaluate the surface finish was Peak-to-valley roughness $\left(R_{t}\right)$ since information on the relative height of the microtopography is more representative of the surface finish. It is well established that under ideal cutting conditions, the machined surface profile is formed by the replication of the cutting tool tip onto the workpiece surface at feed per revolution intervals. The theoretical value of surface roughness achievable during turning with a round nose tool can be approximately given by the kinematic roughness equation:

$$
\mathrm{R}_{\mathrm{t}}=(f)^{2} / 8 \cdot \mathrm{R}_{\mathrm{p}}
$$

where $f$ is the feedrate $(\mu \mathrm{m} / \mathrm{rev}), \mathrm{Rp}$ is the tool nose radius $(\mathrm{mm})$ and $R_{t}$ is the maximum height of peak-to-valley $(\mu \mathrm{m})$. This equation is schematically represented in Figure 3.

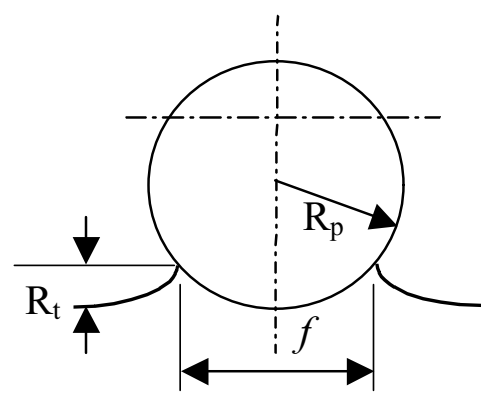

Figure 3. Theoretical surface height Rt for face turning operation.

\section{Microhardness Measurements}

In order to study the effect of the mechanical and metallurgical state on the work hardening of the machined surface layer, the microhardness of the diamond turned surfaces was measured. Microhardness of the machined samples was measured with a BUEHLER Micromet III Digital microhardness tester. A diamond Vicker's Hardness indenter was pressed into the sample using a cycle time of 15 seconds. The indentations tests were performed with several loads: $10 \mathrm{~g}, 50 \mathrm{~g}, 100 \mathrm{~g}, 200 \mathrm{~g}$ e $500 \mathrm{~g}$. Average results of four repeated tests are plotted.

\section{Results and Discussion}

\section{Surface Finish Measurements}

Figures 4-a, 4-b and 4-c present three photomicrographs made by optical Nomarski interference contrast microscopy of the machined samples after cutting $\left(\mathrm{CR}\right.$ - cold rolled, $\mathrm{TG}_{\text {small }}$ - reduced grain size and $\mathrm{TG}_{\mathrm{ar}}$ - as-received,respectively). The samples with the largest feedrate ( $\mathrm{f}=30 \mu \mathrm{m} / \mathrm{rev}$ ) were chosen for two reasons: first to show that no sign of cutting edge damage can be observed within the cutting grooves, and second to show the high fidelity machined groove profile generated on the machined surface. It also should be noticed that the elastic recovery is more pronounced in the as-received sample (Figure 4-c). This qualitative result is also supported by the peak-to-valley roughness result.

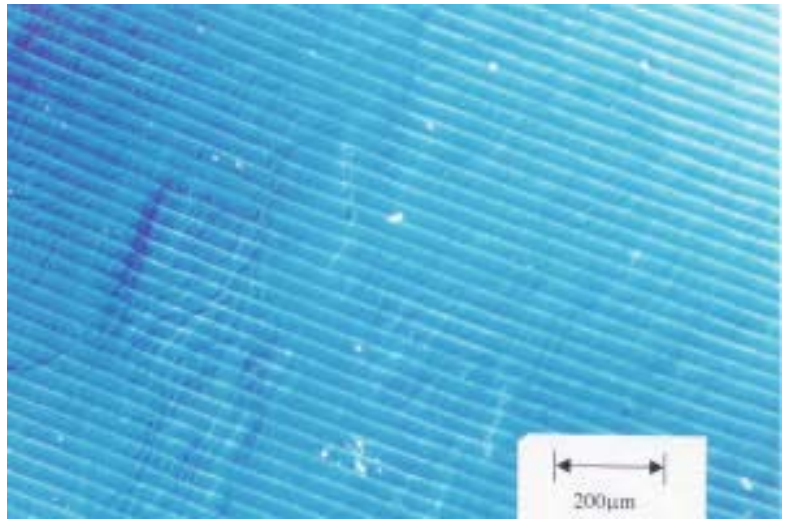

a)Coldrolled.

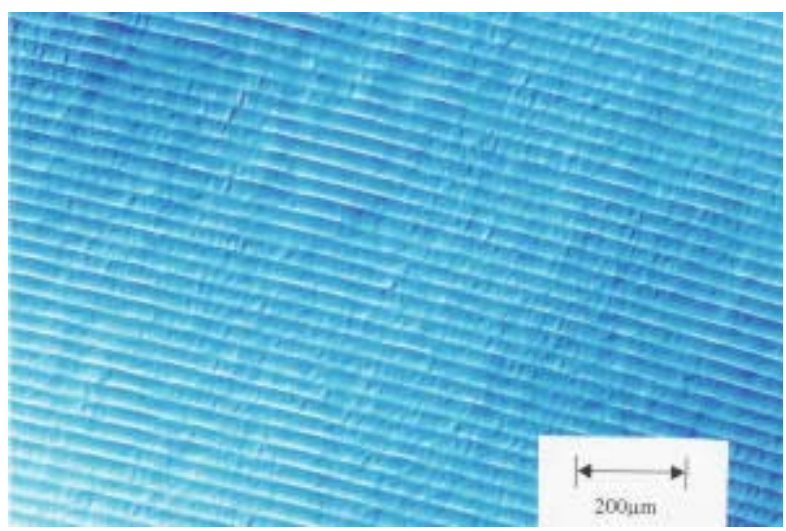

b) $\mathrm{TG}_{\text {small }}$

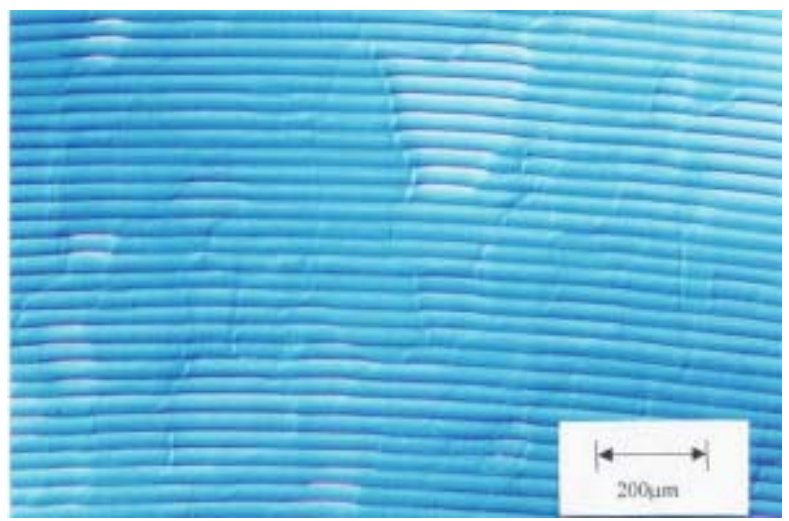

c) $\mathrm{TG}_{\text {as-received }}$

\begin{tabular}{|ll|}
\hline Tool: Single crystal diamond & Cutting conditions: \\
$\mathrm{Rp}=1.52 \mathrm{~mm}$ & feedrate $(f): 30 \mu \mathrm{m} / \mathrm{rev}$ \\
Rake angle $(\gamma): 0^{\circ}$ & depth of cut $(\mathrm{ap}): 10 \mu \mathrm{m}$ \\
Clearance angle $(\alpha): 12^{\circ}$ & Roughness: \\
& a) $R t=171 \mathrm{~nm}$ \\
& b) $R t=154,5 \mathrm{~nm}$ \\
c) $R t=206,3 \mathrm{~nm}$ \\
& Magnification: $100 \mathrm{x}$ \\
\hline
\end{tabular}

Figure 4. Photomicrograph showing the surface finish of both machined samples (a) cold rolled with reduction of $80 \%$; (b) refined grain (TGsmall) and c) As received machined surface (TGar).

The lowest values are present in the grain refined sample. As the cutting edge length in contact with the grains increased, the material may have behaved more homogeneously than the as-received one and the strain elastic recovery was less pronounced.

The effect of depth of cut on peak-to-valley roughness is shown in Figure 5. It was found that the peak-to-valley roughness varied with increasing depth of cut. However, no systematic relationships 
were found between depth of cut and the roughness value. For smaller values of depth of cut (from $5 \mu \mathrm{m}$ up to $15 \mu \mathrm{m}$ ) the roughness behaviour differed from the expected in that a greater depth of cut is supposed to produce a greater roughness. When the depth of cut reached $30 \mu \mathrm{m}$ the surface roughness also increased. This was more evident in the cold rolled sample. In addition, the surface roughness is larger for the CR sample when compared to the other samples.

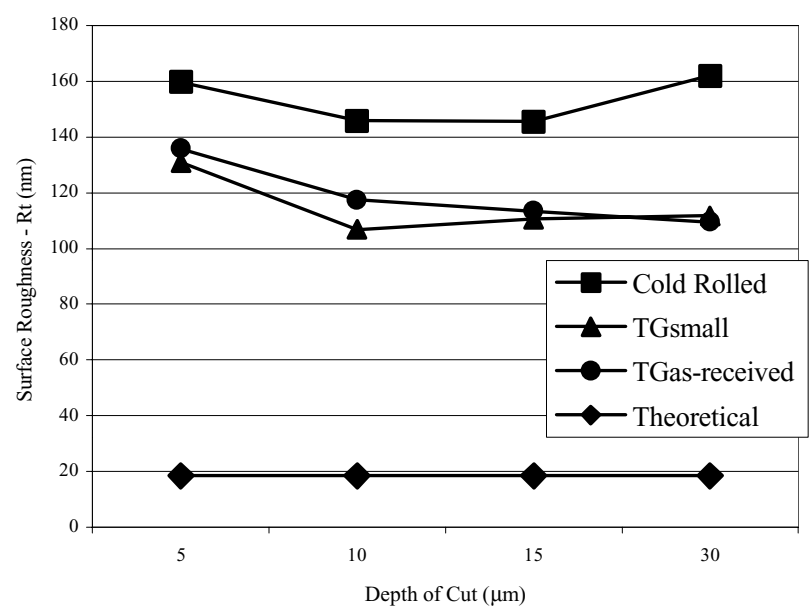

Figure 5. Comparison among the experimental values of surface roughness as function of the depth of cut (15 $\mu \mathrm{m} / \mathrm{rev}$ constant feedrate) for the three samples assessed.

Figure 6 shows the values of the maximum surface roughness $\left(R_{t}\right)$ of the machined samples as a function of the feedrate. The experimental values are always larger than the theoretical values estimated using equation (1). For lower values of feedrate $(5-10$ $\mu \mathrm{m} / \mathrm{rev}$ ) the surface roughness of the cold rolled sample presented the smallest values. The difference observed in the surface roughness values may be attributed to the strength of the machined materials. The results showed in Figure 6 also corroborate well with the results presented by Hwang \& Zhang, (1993) of cutting tests with aluminium alloy (6061-T6) and carbon steel (AISI-1020). According to these authors these differences in amplitude of the surface roughness profile may be attributed to the elastoplastic deformation and to the elastic recovery process, which are more prominent in higher strength materials such as carbon steel (AISI 1020) than in lower strength materials such as aluminum alloy. Since the cold rolled material is capable of sustaining less plastic deformation because the work hardening, the surface roughness is expected to be smaller.

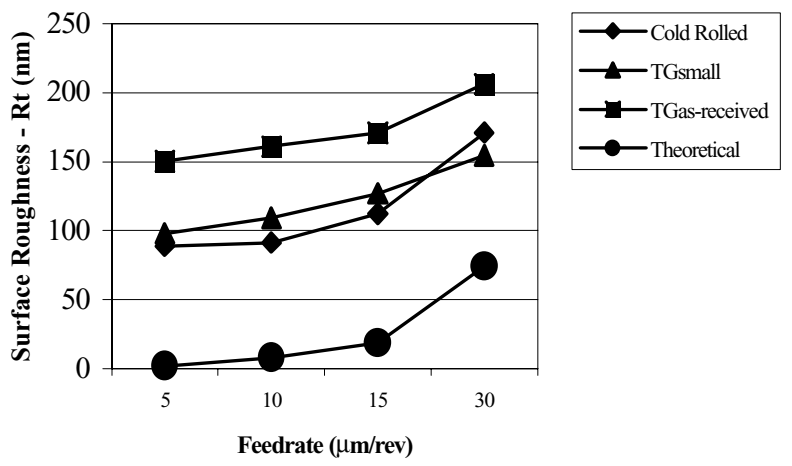

Figura 6. Comparison between the theoretical and experimental values of surface roughness as function of the feedrate (10 $\mu \mathrm{m}$ depth of cut).
During diamond turning, the workpiece material swells at the end of the active cutting edge (Sata et. Al., 1985). As shown in Figure 7, this is due to the plastic side flow (Shaw, 1984) in which the metal left behind on the cutting edge is subjected to sufficiently high pressure to cause the metal to flow to the side of the active cutting edge. Furthermore, the cutting force along the main cutting edge of the tool (Ft in Figure $7 \mathrm{~b}$ )), which is required to provide two-dimensional cutting along the edge, pushes aside the work material near the tool nose causing it to flow to the free surface (Sata, et al.1985). In the region below the chip, complicated elastic and plastic deformation occurs (Whitehouse, 1994) which is caused by the indentation and/or burnishing by the cutting edge. As shown in Figure 1, the workpiece material left behind the front clearance of the tool springs back or recovers after burnishing. The combined effect of plastic side flow, burnishing and elastic recovery will cause greater and deeper tool marks to be formed on the machined surface and this is referred in this work as the materials swelling. The amount of swelling depends on the properties of the material being cut. The softer and more ductile the material, the greater will be the swelling effect [Sata et al. 1985].

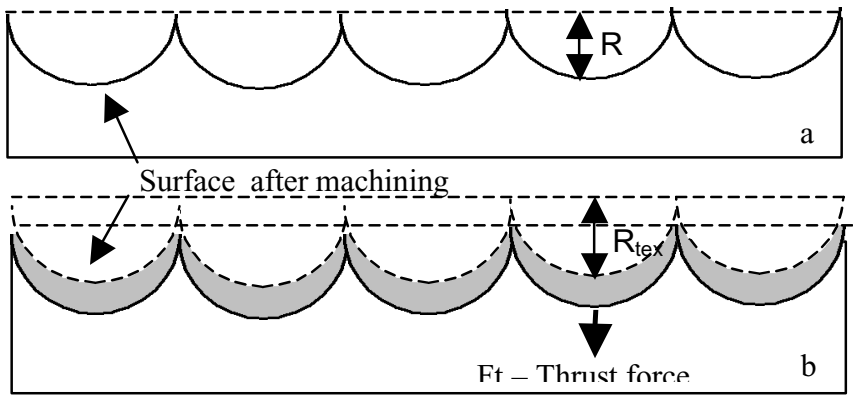

Amount of

Figure 7. Effect of strain elastic recovery on surface peak-to-valley heights. The elastic recovery wil be more pronounced within material with larger elastic module, a) theoretical surface roughness (ideal height) and b) surface roughness height after machining (Chan 2001).

The degree of work hardening caused by machining will be determined by measuring the surface microhardness. Also, the technique of recrystallizing the surface outmost layer will be considered to observe the effect of the work hardening. However, the quantitative estimation of the extension into the workpiece cannot be considered by either forms.

\section{Microhardness of the Diamond Turned Surfaces}

Figure 8 shows the microhardness values measured for the machined samples. It can be observed that the microhardness value of the cold rolled (CR) sample is always greater than the workpiece with small grain size. 


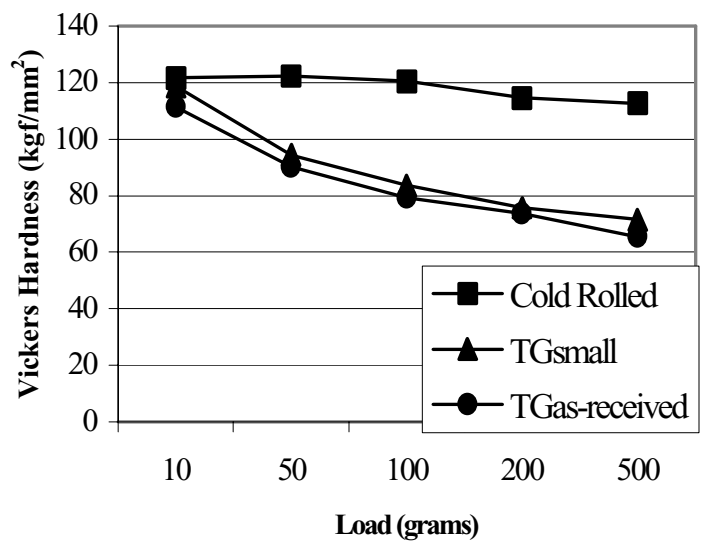

Figure 8. Microhardness Vickers variation as a function of the load applied for different machined workpiece.

Despite the microhardness increase at the lowest loads for both $\mathrm{TG}_{\text {small }}$ and $\mathrm{TG}_{\mathrm{ar}}$ samples, it is worth noticing that the CR sample does not show clear reduction in microhardness with the increase in loading. This effect is more prominent for the $\mathrm{TG}_{\text {small }}$ sample. The smaller values of microhardness for larger loads may be attributed to the $\mathrm{TG}_{\text {small }}$ sample being prone to remaining surface strain hardening.

Furthermore, for lower loads such as $10 \mathrm{~g}$, the surface microhardness of the $\mathrm{TG}_{\text {small }}$ machined sample and the as-received samples are similar to that of the CR workpiece. In this case, since the penetration depth of the indenter is very shallow it is possible to assert that the microindentation process occurred within the work hardened layer generated by the tool/workpiece material interaction during cutting. As the indentation load increases, the work hardened layer effect upon microhardness is attenuated. Moreover, the surface strain hardening level found at the surface vicinity of the $\mathrm{TG}_{\text {small }}$ and as-received samples might be of the same order of magnitude of the strain imposed by the $80 \%$ reduction during cold rolling process. It is worth mentioning that the damaged layer, in this situation, might be very low, since for subsequent larger loads, the microhardness values present a rapid decreasing tendency.

This effect is more prominent for the as-received sample. The smaller values of microhardness for larger loads might be attributed to a remaining surface strain hardening tendency of the as-received sample. Furthermore, for lower loads such as $10 \mathrm{~g}$, the surface microhardness of the $\mathrm{TG}_{\text {small }}$ machined sample is similar to that of the CR workpiece. In this case, since the penetration depth of the indenter is very shallow, it is possible to assert that the microindentation process occurred within the work hardened layer generated by the tool/workpiece material interaction during cutting. Although the indentation mark will also undergo an elastic recovery, the theoretical penetration depth for the lowest load (i.e., $10 \mathrm{~g}$ ) will be approximately $3.1 \mu \mathrm{m}$, for diagonal size of $15.4 \mu \mathrm{m}$. This is schematically represented in Figure 9.

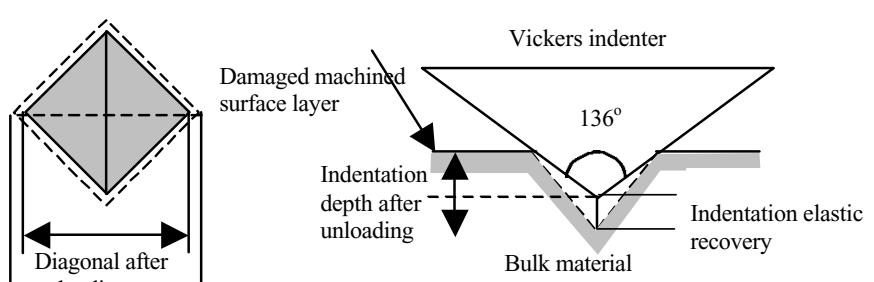

b)

Diagonal during

loading

Figure 9. Schematic diagram of the Vickers pyramid indenter pressed into the deformed machined layer; a) indentation mark and b) indentation elastic recovery after unloading.

Figure 10 shows a very interesting photomicrograph of the measurement of microhardness in this $\mathrm{Al}-\mathrm{Mg}$ alloy. It can be observed that the indentation mark deviates a bit from one grain to another. The load for this case was $1000 \mathrm{~g}$ being the reference surface used as the nominal microhardness of the workpiece. It is worth mentioning that microhardness uses loads equal and smaller than $200 \mathrm{~g}$.

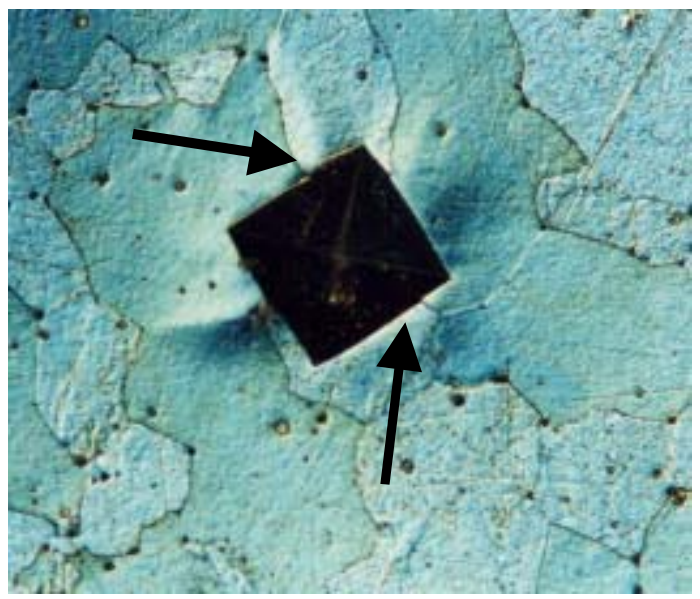

Figure 10. Photomicrograph of the sample used to measure the nominal microhardness (load $1000 \mathrm{~g}$ and magnification 200x).

\section{Recrystallization of the Diamond Turned Surfaces}

The as-received sample was re-crystallized in order to observe the effect of work hardening on the machined surface. Cross section analysis was tried in order to obtain information on the extent of the work hardening caused by diamond machining into the subsurface. However, no result was obtained by means of observing the cross section of the machined surface.

Figure 11 shows the machined surface of the as-received sample after the re-crystallization. No sign of recrystallization was observed either. This result corroborate with work hardening observed for small loads. The work hardened layer might be so thin that the amount of work hardened material is not sufficient for the nucleation of new grains. 


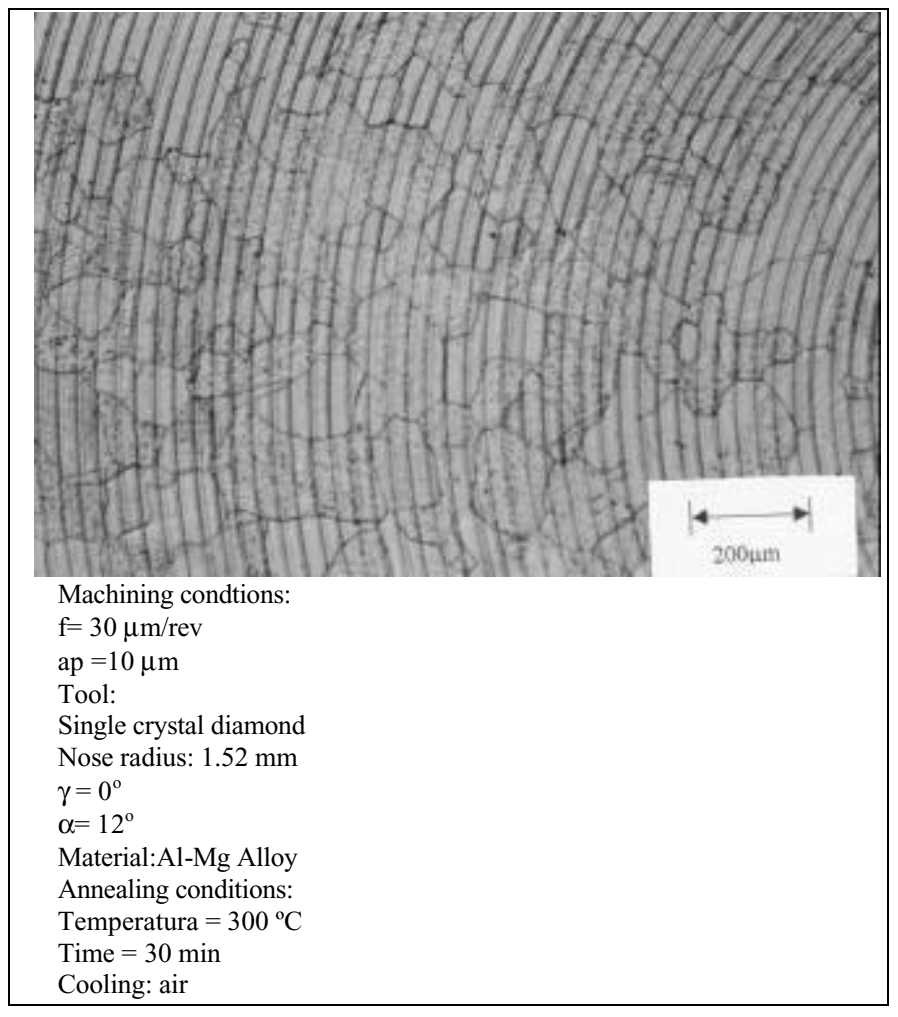

Figure 11. Surface submitted to annealing after machining in order to detect work hardening by means of recrystalization. Surface etched with Kellers reagent (etchant).

\section{Material Removal: Chip Morphology and Topography}

One of the expected results of this work was to find the difference in chip morphology and topography. It was proposed that, when the material is metallurgically or mechanically modified, the chip formation is less affected by anisotropy. Figure 12 presents photomicrographs of chips removed from the workpieces under the same cutting conditions. Figure 12-a depicts the surface microtopography and morphology of the lamella structure. It can be seen that the lamella thickness varies from grain to grain. This is a result of the random crystallographic orientation of the crystal grains. The same effect is also observed in the chip removed from the workpiece with reduced grain size as shown in Figure 12-b. However, it is worth mentioning that, in ultraprecision diamond turning, the tool cuts within the range of a single grain. Based upon that, as the grain size is reduced the number of grains cut at the same time is much larger than the as-received sample.

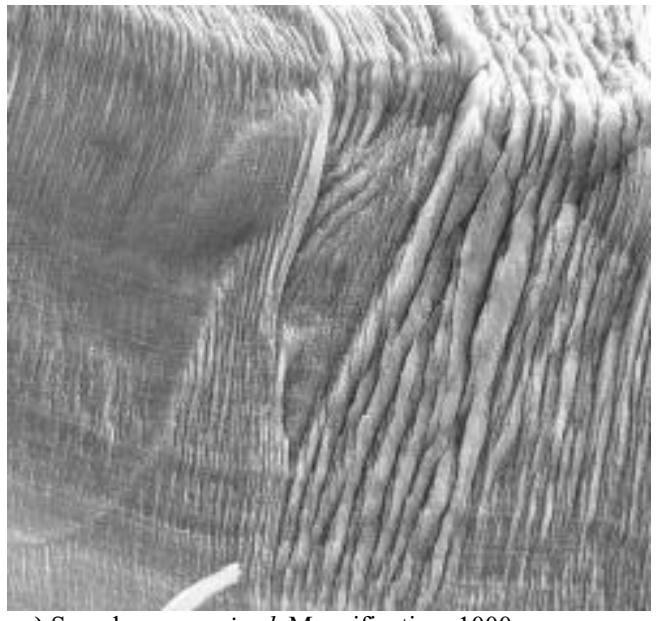

a) Sample: as-received. Magnification: 1000x Cutting conditions: $f=30 \mu \mathrm{m} / \mathrm{rev}$, ap $=10 \mu \mathrm{m}$

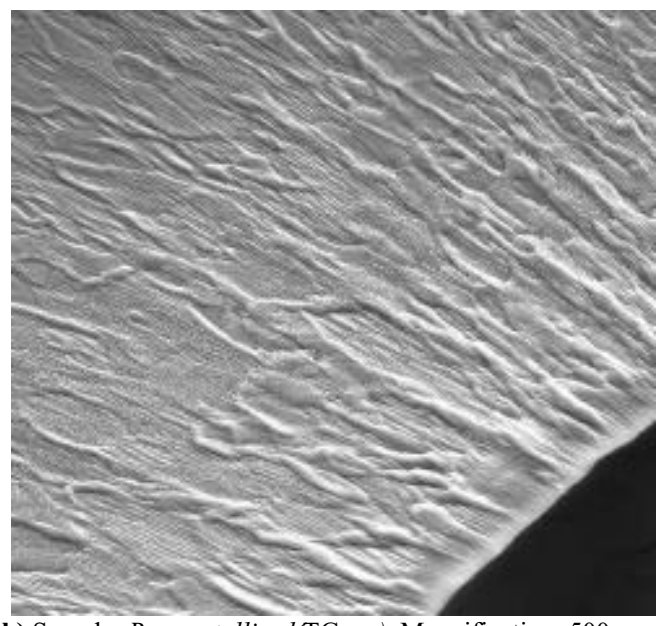

b) Sample: Re-crystallized ( $\left.\mathrm{TG}_{\text {small }}\right)$. Magnification: $500 \mathrm{x}$

Cutting conditions: $f=30 \mu \mathrm{m} / \mathrm{rev}$, ap $=10 \mu \mathrm{m}$

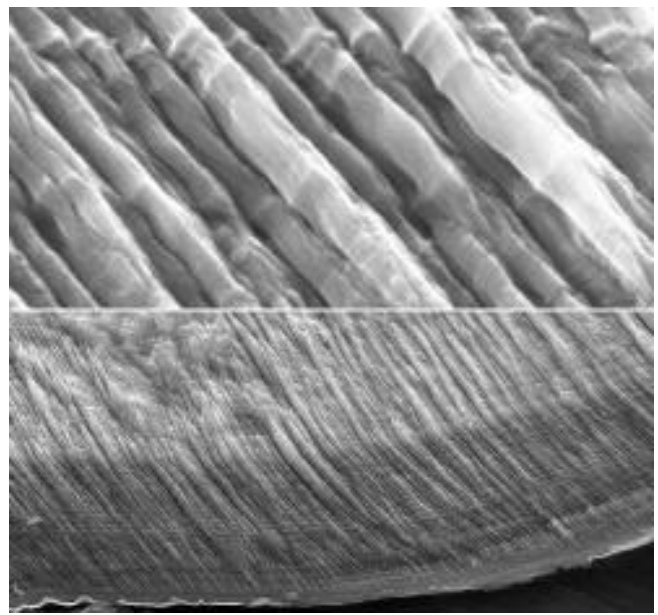

c) Sample: Cold rolled. Magnification: Top: $10.000 \mathrm{x}$

Bottom: $1000 \mathrm{x}$. Cutting conditions, : $f=30 \mu \mathrm{m} / \mathrm{rev}$, ap $=10 \mu \mathrm{m}$

Figure 12. Photomicrographs made by scanning electron microscope of the chips removed from the three different samples diamond turned.

The effect of anisotropy might be attenuated in this case. Figure $12 \mathrm{c}$ ) depicts the chip removed from the cold rolled sample. In this case, it is observed that the lamella microstructure do not show thickness variation along the chip cross-section as it is observed in 
the former image. This is attributed to the fact that cold rolling helps to generate homogeneous properties of the polycrystalline aggregate. This would provide texture to the crystal grains, i.e., grain with preferred orientation. As a result, the behavior of the polycrystalline material is similar to a single crystal. In addition, since cold rolling tends to make material more homogeneous, the shear angle variation will be lower as well. On the other hand, shear angle variation will be more prominent in the $\mathrm{TG}_{\mathrm{ar}}$ once the random orientation of the grains will be responsible for material anisotropy during machining. This can be better understood by the variation of lamella thickness in Fig. 12 a).

\section{Conclusions}

This work showed experimental results of ultraprecision machining of mechanically and metallurgical modified Al-Mg alloy. The workpieces were face machined with a single point monocrystalline diamond tool. The cold rolled workpiece presented larger values of surface roughness than the refined grain sample. This was attributed to the difference in strength between the two work materials used. The maximum surface roughness $\left(R_{t}\right)$ showed values always inferior to $120 \mathrm{~nm}$ for the refined grain sample for feedrates smaller than $15 \mu \mathrm{m} / \mathrm{rev}$.

The microhardness of refined grain sample also showed a decreasing trend with an increase in load. This was attributed to the to a remaining surface strain hardening tendency of the material. For very small load (i.e., $10 \mathrm{~g}$ ) it was observed that the microhardness of the $\mathrm{TG}_{\text {small }}$ sample is similar to the value of the cold rolled sample. The cold rolled machined sample did not present a noticeable variation in microhardness with the load. It may be accepted that the material should have reached its strain hardening limit.

\section{Acknowledgements}

The authors would like aknowledge the financial support of Fundação de Amparo à Pesquisa do Estado de São Paulo (FAPESP) and Conselho Nacional de Desenvolvimento Científico e Tecnológico (CNPq). The authors also would like to thank Eng.
MSc Helder Augustus Treviso da Silva for his contributions to this work.

\section{References}

Callister Jr., W. D., 1994 "Material Science and Engineering- an introduction", Chapter 7, J. Willey \& Sons, $3^{\text {rd }}$ edition, New York, 811p..

Chan, K.C., Cheung, C.F., Ramesh,M.V., Lee, W.B., To S.; 2001 "A theoretical and experimental investigation of surface generation in diamond turning of an Al6061=SiCp metal matrix composite" Int. J. of Mech. Sc.Vol. 43, pp. 2047-2068.

Duduch, J.G., Porto, A. J. V., Rubio, J. C. C. Jasinevicius, R. G., 2000 La Influencia del Numero de Pasadas en la calidad de las Superficies Ópticas de Reflección. Revista Información Tecnológica del Chile, Chile: , Vol. 11, n.4, pp.53 - 58.

Evans, C., Polvani, R., Postek, M., Rhorer, R., 1987, "Some observations on tool sharpness and sub-surface damage in single point diamond turning", SPIE - In Process Optical Metrology for Precision Machining, Vol. 802, pp. 52-66.

Furukawa, Y., Moromuki, N., 1988, "Effect of material properties on ultra precise cutting process", Annals of the CIRP, Vol. 37, n. 1, pp. 113116 .

Horio, K., Kasai, T. Ogata, Y., Kobayashi, A., 1992, “A study on damaged layer remaining in diamond mirror cut surface", Annals of the CIRP, Vol. 41, n. 1, pp. 137-140.

Hwang, T-W, Zhang, G. 1993 "Analysis of elastoplastic deformation observed on machined surfaces" Manufacturing Science and Engg. - ASME Winter Annual Meeting, New Orleans, Lo, USA, Nov.28-Dec. 3, Vol. 64, pp.553-562.

Jasinevicius, R.G.; Duduch, J.G.; Porto, A.J.V.; Purquério, B.M., 1999, "Critical aspects on the behavior of material from the mechanical toolworkpiece interaction in single point diamond turning", RBCM - J. of the Braz. Soc. Mechanical Science, Vol. XXI, n. 3, pp. 509-518.

NBR6405, 1988, "Rugosidade da Superfície", ABNT.

Sata, T.; Li, M.; Takata, S.; Hiraoka H.; Li, C.Q.; Xing, X.Z.; Xiao, X.G., 1985, "Analysis of surface roughness generation in turning operation and its applications", Annals of the CIRP, Vol. 34, n 1, pp. 473-476.

Sato, M., Kato, Y., Apki, S., Ikoma, A., 1983"Effects of Crystal Orientation on the Cutting Mechanism of the Aluminum Single Crystal" Bull. of the JSME, Vol.26(215), pp.890-896.

Whitehouse DJ. 1994 "Handbook of surface metrology". Bristol, Philadelphia: Institute of Physics Pub.. 